ARTICLE

https://doi.org/10.1038/s41467-019-13750-w

\title{
Cascading and pulse-like ruptures during the 2019 Ridgecrest earthquakes in the Eastern California Shear Zone
}

Kejie Chen ${ }^{1,2 \star}$, Jean-Philippe Avouac (10 ${ }^{1}$, Saif Aati (1) ${ }^{1}$, Chris Milliner $\mathbb{( B D}^{3}$, Fu Zheng ${ }^{4} \&$ Chuang Shi $^{4}$

On July 4 2019, a $M_{w} 6.5$ earthquake, followed 34 h later by a $M_{w} 7.1$ event, struck Searles Valley, California. These events are part of a long-lived cluster of historical earthquakes along the Eastern California Shear Zone (ECSZ) which started in 1872 and are associated with temporarily elevated strain rates. We find that the $M_{w} 6.5$ event initiated on a right-lateral NW striking fault and then ruptured a left-lateral fault to the surface. This event triggered right-lateral slip during the $M_{w} 7.1$ earthquake. It started as a bilateral, crack-like rupture on a segment brought closer to failure by the $M_{w} 6.5$ event. The rupture evolved to pulse-like as it propagated at a relatively slow velocity $(2 \mathrm{~km} / \mathrm{s})$ along a segment that was unloaded by the $M_{w} 6.5$ event. It stopped abruptly at the Coso volcanic area and at the Garlock Fault and brought some neighbouring faults closer to failure.

\footnotetext{
${ }^{1}$ Division of Geological and Planetary Sciences, California Institute of Technology, Pasadena, CA 91125, USA. ${ }^{2}$ Department of Earth and Space Sciences, Southern University of Science and Technology, Shenzhen 518055 Guangdong, China. ${ }^{3}$ Jet Propulsion Laboratory, California Institute of Technology, Pasadena, CA 91109, USA. ${ }^{4}$ School of Electronic and Information Engineering, Beihang University, 37 Xueyuan Road, 100083 Beijing, China.

*email: chenkj@sustech.edu.cn
} 
sequence of earthquakes rattled Searles Valley near Ridgecrest, California, in July 2019. The two dominant events, a $M_{w} 6.5$ on July 4 followed 34 h later by a $M_{w} 7.1$ event on July 5 , were felt over most of southern California and caused surface ruptures with minor damage to the nearby towns of Ridgecrest and Trona ${ }^{1}$. These earthquakes occurred within the Eastern California Shear Zone (ECZS), a zone of faulting and seismicity that runs east of the San Andreas Fault (SAF) system and joins with it in the Salton Trough (Fig. 1). The ECSZ includes the faults in Owens Valley along the eastern side of the Sierra $\mathrm{Nevada}^{2}$, and extends southward across the Mojave Desert ${ }^{3,4}$ (Fig. 1). The SAF system, including the San Jacinto fault and ECSZ, accommodate $80 \%$ of the $49 \mathrm{~mm} / \mathrm{yr}$ of the northwestward motion of the Pacific Plate relative to stable North America. However the geodetic and geological data suggest significantly different rates across the ESCZ ${ }^{5}$. Global Positioning System (GPS) and other space based geodetic technique indicate consistently since the 1990 s about $10 \mathrm{~mm} / \mathrm{yr}$ of right-lateral shear ${ }^{5-7}$, while the geologic slip fault rates on the faults are typically of the order or $0.5-2 \mathrm{~mm} / \mathrm{yr}$ and fall significantly short of matching the geodetic strain rate $e^{3,5}$. Conversely, the geodetic strain rate associated with some other faults, the left-lateral Garlock fault in particular, falls short of matching the Holocene geologic slip rate ${ }^{7-9}$.

The 2019 Ridgecrest earthquakes occurred within the exceptionally dense network of continuously recording GPS stations of the Plate Boundary Observatory ${ }^{10}$. Near-field high-rate $(1 \mathrm{~Hz})$ GPS records of large earthquakes are still rare and can provide unique insights into source characteristics ${ }^{11,12}$. Moreover the earthquakes occurred in a desert area that is particularly well

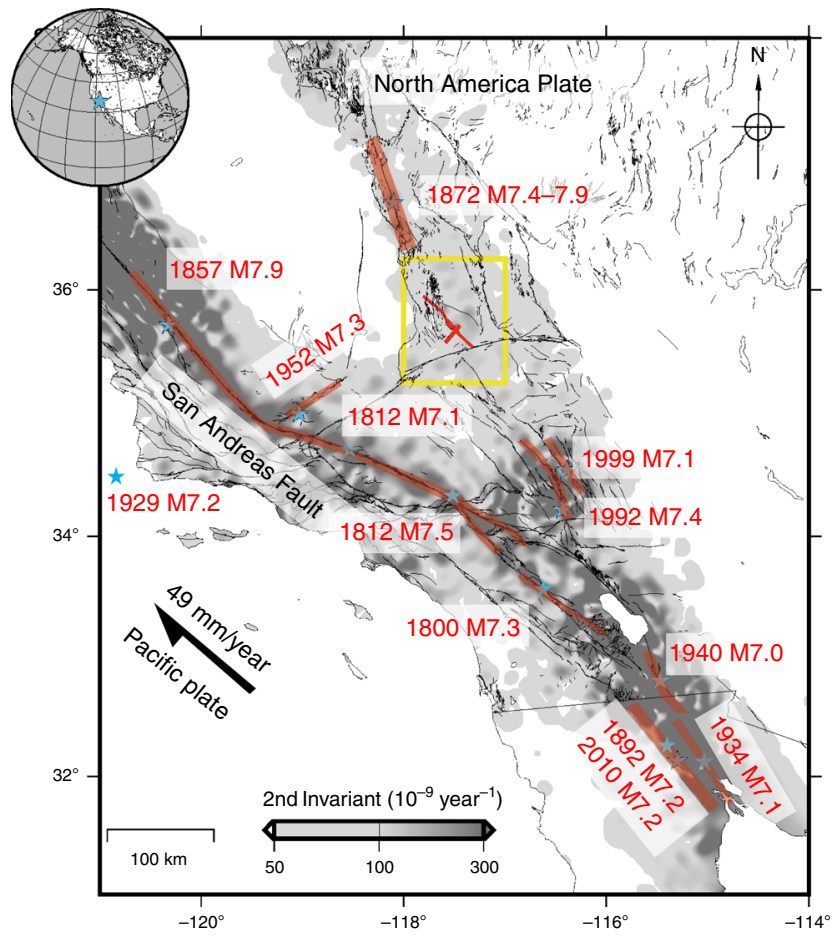

Fig. 1 Setting of the $\mathbf{2 0 1 9}$ Ridgecrest earthquakes. Strain rate over Southern California determined from geodetic measurements ${ }^{50}$ (grey shading). Active faults from the USGS database ${ }^{51}$ (https://earthquake. usgs.gov/hazards/qfaults/). Surface ruptures (red shading) of recent $M>7$ earthquakes in Southern California since 1850 (https://earthquake.usgs. gov/hazards/qfaults/citation.php). The 1800 M7.3 rupture is from Salisbury et $\mathrm{l}^{52}$, the 1812 M7.1 rupture is from Lozos ${ }^{53}$, the 1812 M7.5 rupture is from Toppozada and Branum ${ }^{54}$, The 1892 M7.2 rupture is from Rockwell et al. ${ }^{55}$. Yellow box outlines the footprint of Fig. 2. suited for remote-sensing observations of ground deformation using $\operatorname{radar}^{13}$ or optical images ${ }^{14}$. The rich dataset available makes it not only possible to image the rupture process during the $\mathrm{M}_{\mathrm{w}} 7.1$ rupture and assess how this relates to the fault geometry, but also to study the possible effect of the static stress changes induced by the $M_{w} 6.5$ foreshock. It is indeed generally considered that the fault geometry and pre-existing stresses are primary factors controlling the nucleation, growth and arrest of seismic ruptures ${ }^{15,16}$.

In this study we therefore use remote sensing observations, high-rate GPS geodetic records and seismological waveforms to produce detailed source models of these earthquakes. We draw implications regarding the factors that influence the rupture process during these earthquakes and discuss how they relate to historical seismicity and geodetic strain in the ECSZ.

\section{Results}

Surface deformation measured from optical image correlation. We used optical image subpixel correlation to map the surface ruptures and fault slip. We selected publically-available Sentinel-2 and Planet Labs imagery with ground sample distance of 10 and $3 \mathrm{~m}$, respectively. We used Sentinel-2 images acquired on 28 June and 8 July, so they were acquired before and after the two mainshocks, and Planet Labs images acquired on the 4 and 5 July at 11:11 PST, which allowed for distinguishing of the two events. These images were correlated to estimate the horizontal surface displacement field with a ground resolution on the order of a few hundred meters (Fig. 2). In practice the measurements are affected by various kinds of artefacts due to orthorectification errors, which might be due to inaccuracies of the digital elevation model used by the image providers, or to inaccurate geometric modelling of the images due to the satellite jitter or chargecoupled device (CCD) alignments ${ }^{17}$. Despite the artefacts, the surface ruptures are clearly visible in the offset maps measured from the Sentinel-2 and Planet Labs images (Fig. 2 and Supplementary Fig. 1). Both datasets clearly show one main rupture trending NW, which is visible only in the correlation of images spanning the $M_{w} 7.1$ event and a more minor rupture trending NE which is visible only in the correlation of images spanning the $M_{w}$ 6.5. The measurements from the Sentinel-2 and Planet Labs images are very consistent and were used to map the fault trace for each event. The total fault slip, including the strike-slip and the strike-perpendicular components, are measured from profiles oriented perpendicular to the fault trace and estimated by linear extrapolation of the surface discontinuity across the observable fault-zone (see "Methods" section for details).

Although small geometrical fault-scale complexities can be identified, these measurements show that the $\mathrm{M}_{\mathrm{w}} 7.1$ event produce a nearly continuous fault trace over about $60 \mathrm{~km}$, with an average of $1.60 \pm 0.22 \mathrm{~m}$ of right-lateral surface slip (Fig. 2c). The strike-perpendicular component is very small within uncertainties $(0.30 \pm 0.15 \mathrm{~m})$ so the slip vector is nearly everywhere parallel to the fault trace. The USGS W-phase moment tensor is consistent with these measurements (Fig. 2b).

Similarly, our measurements indicate that the $M_{w} 6.5$ event ruptured a $\sim 15 \mathrm{~km}$ long fault striking $\mathrm{NE}$ with an average of $0.55 \pm 0.08 \mathrm{~m}$ of left-lateral surface slip (Fig. 2d). The strikeperpendicular component is almost null with a small reverse component of $0.08 \pm 0.08 \mathrm{~m}$.

Kinematic source models of the $M_{w} 7.1$ and $M_{w} 6.5$ earthquake. We determine a kinematic source model of the $\mathrm{M}_{\mathrm{w}} 7.1$ earthquake using the remote sensing data to constrain the fault geometry and the static displacements combined with the high-rate GPS and teleseismic records to constrain the time evolution of the 

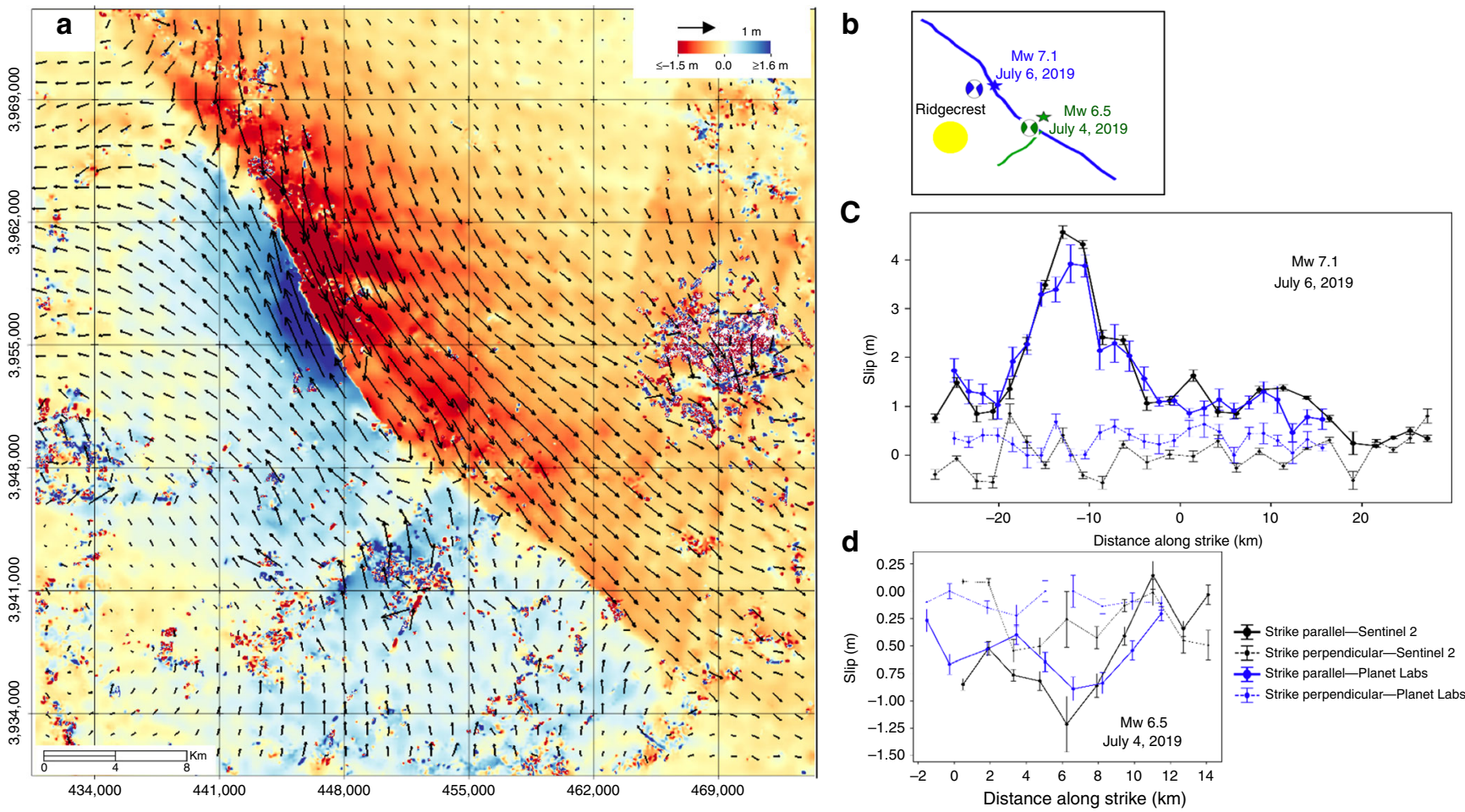

Fig. 2 Surface deformation due to the 2019 Ridgecrest earthquakes measured from optical image correlation. a Surface displacement (arrows) and amplitude of NS component (shading) measured from correlation of Sentinel-2 images acquired on June 28 and July 08, 2019. b Simplified fault ruptures derived from the Sentinel-1 and Planet Labs data with GCMT focal mechanisms and epicentres of the $M_{w} 7.1$ and $M_{w} 6.5$ earthquakes from the USGS. c Strike-parallel (positive for right-lateral) and strike-perpendicular (positive in extension) component of surface fault slip measured from the Sentinel-1 and Planet Labs image. $\mathbf{d}$ Same as $\mathbf{c}$ for the $M_{w} 6.5$ earthquake.

rupture. The fault geometry is constrained from the surface ruptures (Fig. 2) and from the $\mathrm{W}$-phase moment tensor which suggests that the fault dips $85^{\circ} \mathrm{NE}$. We also use line of sight displacements measured from Interferometric Synthetic Aperture Radar (InSAR) provided by the Advanced Rapid Imaging and Analysis (ARIA) Project (https://aria.jpl.nasa.gov/) of the Jet Propulsion Laboratory (See "Methods" section and Supplementary Fig. 6 for image footprints and date of acquisition). We use the GPS records of ground displacement sampled at $1 \mathrm{~Hz}$, along with selected waveforms with a good azimuth coverage from Incorporated Research Institutions for Seismology, and filtered them in the $[0.005,0.4] \mathrm{Hz}$ frequency band (see "Methods" section and Supplementary Fig. 4). We determined a best fitting source model using a least squares procedure with a specified rupture expansion speed using the multiple time window approach ${ }^{18}$ (See "Methods" section and Supplementary Figures for more details). We additionally impose the surface fault slip measured from optical image correlation on the shallowest subfault patches. The SAR measurements show the total displacements due to the $M_{w} 6.5$ and $M_{w} 7.1$ earthquake. However, the model is probably not biased significantly because of the use of the high-rate GPS data and the fact that the fault geometry is constrained from the surface ruptures of only the $M_{w} 7.1$ event. The residuals clearly show a signal consistent with the effect of the $M_{w} 6.5$ earthquake (see Supplementary Fig. 8). We use these residuals to constrain the source model of the $\mathrm{M}_{\mathrm{w}} 6.5$ earthquake. We follow the same procedure for the $M_{w} 7.1$ event by constructing a fault model based on the surface ruptures and $\mathrm{W}$-phase focal mechanism. We impose surface slip to match the measurements from optical image correlation and invert for the slip model that best fits the GPS and teleseismic waveforms as well as the InSAR residuals. The epicentral location and the early aftershocks suggest that the M6.5 event started on a right-lateral fault close to but east of the fault that ruptured in the $M_{w} 7.1$ event. Our source model therefore includes such a fault that didn't break the surface. The best fitting solution fits well the static GPS data, and the remote sensing data, and we therefore consider that the slip distribution on the two nearly orthogonal faults is reasonably well constrained. The details of the rupture kinematics are not well resolved as suggested by the misfit between the predicted and measured GPS waveforms.

\section{Discussion}

The earthquake catalogue of the Southern California Seismic Network shows that the Ridgecrest sequence started with a sequence of foreshocks which were detected within $10 \mathrm{~km}$ of the epicenter of the $M_{w} 7.1$ event (Fig. 3a). The largest earthquake preceding the $M_{w} 6.5$ foreshock was a $M_{w} 4.0$ earthquake 30 min earlier. According to our model (see Fig. S6), the $M_{w} 6.5$ earthquake itself is a compound event which initiated on the rightlateral NW striking fault, released half of the moment, and then activated the left-lateral fault. It released a total moment of $7.43 \times$ $10^{18} \mathrm{~N} \cdot \mathrm{m}$ (equivalent to $M_{\mathrm{w}} 6.5$ ) in about $10 \mathrm{~s}$. Earthquakes with magnitude up to $\mathrm{M}_{\mathrm{w}} 5.4$ swarmed for $34 \mathrm{~h}$ around the two fault planes that were activated during the $\mathrm{M}_{\mathrm{w}} 6.5$. Then, on July 5, one event was able to grow bigger and evolved into the $M_{w} 7.1$ mainshock. Our kinematic source model shows that, during this event, a total moment of $4.85 \times 10^{19} \mathrm{~N} \cdot \mathrm{m}\left(\mathrm{M}_{\mathrm{w}} 7.06\right)$ was released in about $23 \mathrm{~s}$ (Fig. 3a). The rupture initiated on segment F2 (striking N-NW), a fault segment that was brought closer to failure by the $M_{w} 6.5$ event (Fig. 3c). We estimate the static Coulomb stress increase ${ }^{19}$ at the location of the hypocenter to have been 0.2 MPa. The rupture expanded as a crack up-dip and bilaterally during the first $11 \mathrm{~s}$ (Fig. 4 and Supplementary Movie 1), leading to up to $\sim 5 \mathrm{~m}$ of slip on segment F2 (Fig. $3 \mathrm{~b}$ ). 

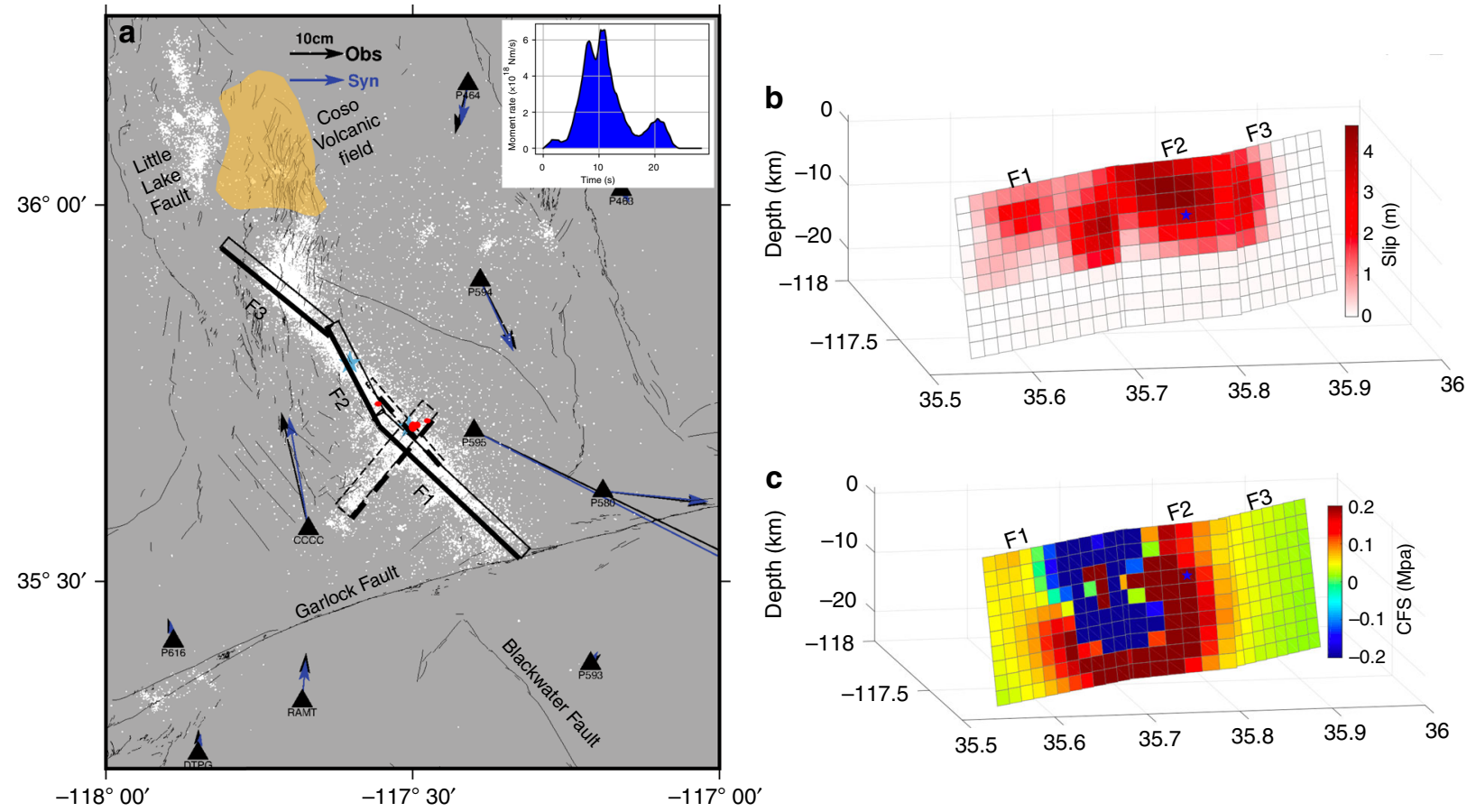

Fig. 3 Source model of the $\mathbf{M}_{\mathbf{w}} \mathbf{7 . 1}$ earthquake of July 6, 2019. a Co-seismic GPS measurements (black arrow) and synthetics (blue arrow). White dots show seismicity after the $M_{w} 6.5$ event until 1 August, 2019, red dots are foreshocks. The catalogue is from the Southern California Seismic Network which is available on-line (https://scedc.caltech.edu/eq-catalogs/index.html). Solid and dashed rectangle outlines projections of the faults adopted in this study for the $M_{w} 7.1$ and $M_{w} 6.5$ events, respectively, and the thick edges are at the surface. Left top corner, moment rate function derived. $\mathbf{b}$ Model of the slip distribution for fault F1, F2 and F3, the blue star shows the hypocenter location. c Coulomb Stress Failure on the fault of the $M_{w} 7.1$ event induced by the $M_{w}$ 6.5 earthquake, note that the color bar is saturated.

From then on, it expanded as a narrow slip-pulse that propagated southeastward on segment F1 and northwestward on segment F3. The pulse died rapidly along the northernmost segment F3 as the rupture approached the Coso volcanic area. However, it was able to propagate over $30 \mathrm{~km}$ along the southernmost segment $\mathrm{F} 1 \mathrm{until}$ its termination at the intersection with the Garlock fault. The rupture front expanded throughout the rupture process at a rate of $2 \mathrm{~km} / \mathrm{s}$ (see "Methods" section and Supplementary Fig. 11 for the determination of the rupture velocity). The slip velocity reached a maximum of about $2 \mathrm{~m} / \mathrm{s}$ on segment $\mathrm{F} 2$. The width of the pulse is estimated to have been $5 \mathrm{~km}$ and was associated with a peak slip velocity $0.5-1 \mathrm{~m} / \mathrm{s}$.

It should be noted that the source parameterization adopted in this study does not enforce a pulse-like rupture. As a result, the transition to pulse-like rupture after $\sim 11 \mathrm{~s}$ into the rupture process is a remarkable feature of this earthquake which is required by the high-rate GPS and seismological records. Pulse-like ruptures have long been inferred from seismological observations ${ }^{20}$ and have now been documented repeatedly in particular thanks to the increasing availability of near-field high-rate GPS records ${ }^{12}$. The reasons for pulse-like ruptures are still debated. They might reflect geometric effects but seem to require, in any case, strong velocity weakening friction on the fault ${ }^{21}$. The initial stress can be a factor too: both theoretical and experimental studies show a transition from pulse-like to crack-like ruptures occurs as the pre-stress increases ${ }^{22,23}$. This factor could have played a role during the $M_{w} 7.1$ event. It is indeed intriguing that the rupture initiated and expanded as a crack on F2 where the static Coulomb stress increased substantially due to the $M_{w} 6.5$ event, but propagated as a pulse on the segment where the stress level decreased (F1) or didn't increase much (F3) (Fig. 3c). The stress variations due to the $\mathrm{M}_{\mathrm{w}} 6.5$ events are, however, small compared with the stress drop during the $M_{w} 7.1$ event, which is estimated to have an average of $\sim 10 \mathrm{MPa}$ using the energy-based approach of Noda et al..$^{24}$. It is possible that due to their orientation, F1 and F3, which both strike NW $\left(313^{\circ}\right.$ and $305^{\circ}$, respectively), were initially both under lower Coulomb stress than F2, which strikes NNW $\left(333^{\circ}\right)$.

The $M_{w} 7.1$ rupture reached close to the intersection of $F 1$ with the Garlock Fault suggesting a geometric control at its southern termination. To the north, the rupture arrested close to the Coso volcanic area where a zone of high heat flow encompasses an area containing numerous Pleistocene volcanic vents and domes ${ }^{25}$ (Fig. 3a). The northern termination of the $M_{w} 7.1$ event is reminiscent of the arrest of the Kumamoto earthquake close to the Aso volcanic system ${ }^{26}$. High pore pressure due to the hydrothermal activity and higher crustal temperatures may have favoured fault creep at shallow depth. The resulting reduced stress level could then have inhibited the propagation of the rupture during the $M_{w} 7.1$ event. It could have also inhibited aftershocks, as was also observed at Aso volcano following the Kumamoto earthquake ${ }^{26}$, as well as remotely triggered earthquakes ${ }^{27}$.

Interestingly, the 2019 Ridgecrest earthquakes seem to be part of a cluster of large events concentrated along the ECSZ. The cluster includes the 1992, $\mathrm{M}_{\mathrm{w}} 7.3$ Landers and the 1999, $\mathrm{M}_{\mathrm{w}} 7.1$ Hector Mine earthquakes in the Mojave Desert (Fig. 1). A few M $>6$ earthquakes had additionally occurred earlier in the area, namely the M6.5 Manix Lake earthquake, and two more minor ( M6) events in 1975 and 1979. Farther north, the ECSZ produced a major earthquake in 1872 with right-lateral ruptures over a distance of about $120 \mathrm{~km}^{28}$, which is estimated to have been as large as $M_{w}$ 7.8-7.9 and was one of the largest historical events in California ${ }^{29}$. These events are close in time given that most faults in the ECSZ (with exception of the Garlock fault) that have been studied for its paleoseismology exhibit a recurrence interval of $6-10 \mathrm{ka}$ or longer. This clustering at the regional scale is 

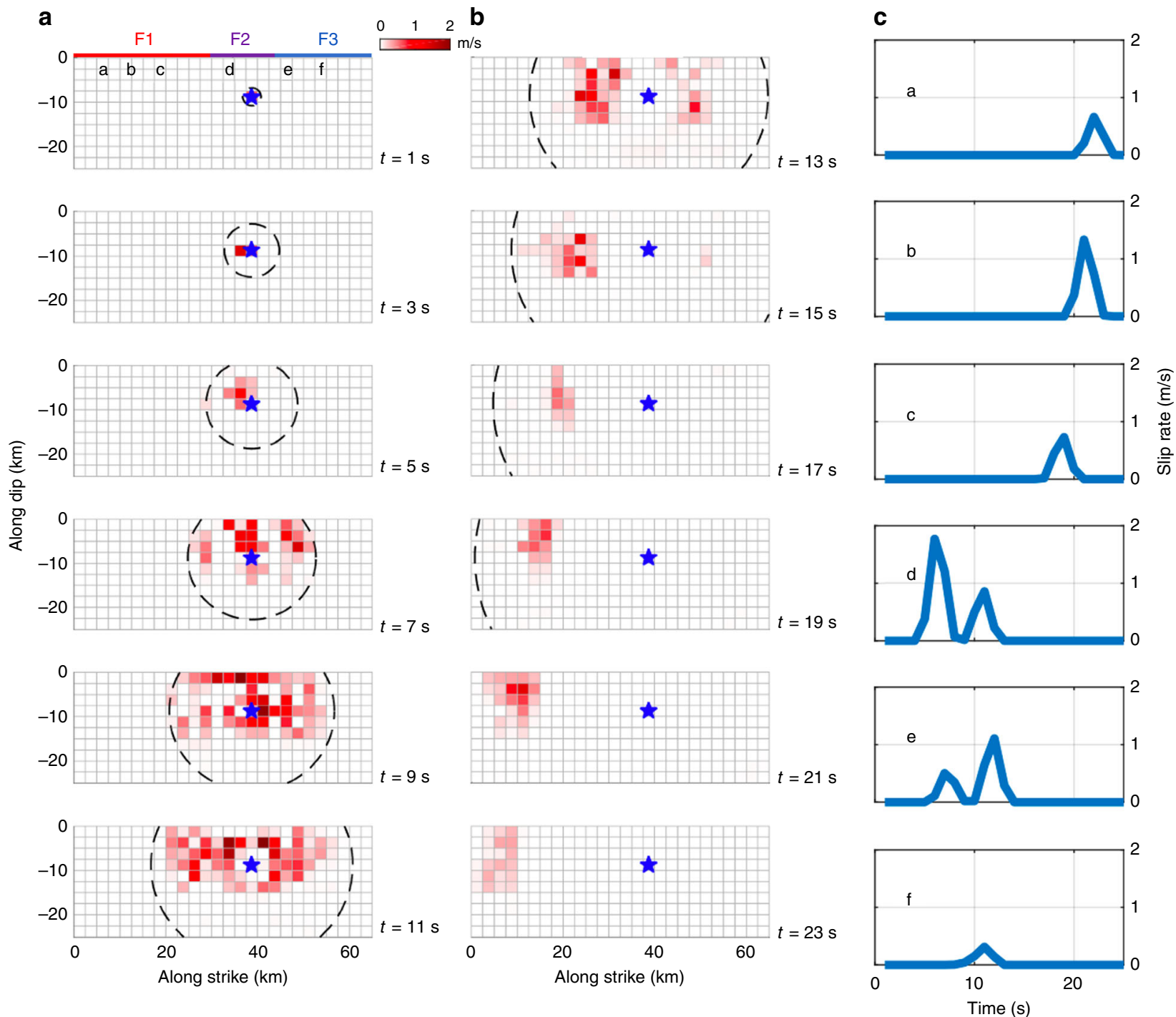

Fig. 4 Time evolution of the rupture during the $\mathbf{M}_{\mathbf{w}} \mathbf{7 . 1}$ Ridgecrest earthquake. $\mathbf{a}, \mathbf{b}$ Snapshots of the rupture expansion history every two seconds. Colours shading indicates the fault slip rate average over $2 \mathrm{~s}$ intervals. The black dashed contour presents the pseudo-rupture front with a rupture velocity of $2.0 \mathrm{~km} / \mathrm{s}$. F1, F2, F3 correspond to the faults in Fig. 3. c Presents slip rate at the six locations in a. Time is relative to the hypocentral origin.

somewhat surprising as geodetic strain rates within the ECSZ accounts for only about $20 \%$ of the relative plate motion, compared with more than $60 \%$ on the rest of the SAF system. The fact that the geodetic rate exceeds geological rates suggests however that the cluster is possibly associated with an on-going pulse of geodetic strain rates $4,30,31$.

The remote-sensing, seismological and geodetic data assembled in this study make it possible to describe the details of how the 2019, Ridgecrest earthquake sequence unfolded. It reveals a sequence of triggering, where small foreshocks initiated on a secondary fault which produced a complex rupture of two conjugate faults on July 4, leading to the eventual triggering of the $\mathrm{M}_{\mathrm{w}} 7.1$ event on July 5. The larger event was possibly arrested due to a combination of geometric (at the intersection with the Garlock fault), and probably hydromechanical (at Coso) effects. The rupture evolved from a crack-like to a pulse-like rupture. This evolution correlates with strike changes and the co-seismic stress changes due to the $\mathrm{M}_{\mathrm{w}} 6.5$ event. These features are noteworthy as they are qualitatively consistent with theory in principle, but further investigations based on dynamical simulations will be needed for a more quantitative test.
With regard to seismic hazard, the Ridgecrest sequence belongs to a late Holocene and historical cluster of seismicity in the ECZS, which includes the 1872 Owens Valley earthquake and the more recent 1947 Manix Lake, 1992 Landers, and 1999 Hector Mine events, all of which are associated with a zone of elevated strain rate measured from geodesy and remote sensing ${ }^{5-7}$. The highstrain rate is probably transient in view of the lower rate derived from geological studies ${ }^{3}$ and might explain the regional clustering of large magnitude earthquakes that seem to characterize this area ${ }^{4,30,31}$ and which is not taken into account in seismic hazard studies. A number of faults adjacent to the Ridgecrest ruptures that belong to the same zone of elevated high strain, and have not ruptured recently, must have been brought closer to failure. They include the Little Lake Fault, which connects the northern end of the recent $M_{w} 7.1$ rupture with the Owens Valley Fault ${ }^{32}$, and several right-lateral faults south of the Garlock Fault, including in particular the Blackwater Fault ${ }^{3}$. The Garlock fault itself was unclamped west of its intersection with the $M_{w} 7.1$ rupture. Further earthquakes rupturing some of these faults in the future would be a natural continuation of the historical cluster although we admit that the significance and cause of this cluster are open questions. 


\section{Methods}

Optical image correlation of Sentinel-2 and Planet Labs images. In order to assess the horizontal surface displacement induced by the two earthquakes $\left(M_{w} 6.5\right.$ and $M_{w} 7.1$, we applied subpixel image correlation using the COSI-Corr technique $^{33}$. Two Copernicus Sentinel-2 orthorectified-optical imagery covering the Ridgecrest region were selected before and after the two earthquakes. Pre and postearthquake images were acquired, respectively, on June 28, 2019 ( 7 days before the $M_{w} 6.5$ earthquake) and on July 8, 2019 (3 days after the $M_{w} 7.1$ earthquake).

Sentinel-2 has a ground sampling distance of $10 \mathrm{~m}$ and is available in four different wavelengths (band 2-Blue, band 3-Green, band 4-Red and band 8-NIR). We correlated each band using the phase correlator of COSI-Corr which can in principle yield an accuracy of 1/50 pixel. A sliding multiscale window was used iteratively in two steps, a size window of $64 \times 64$ pixels $\left(640 \times 640 \mathrm{~m}^{2}\right)$ was chosen for the first step of the correlation, before iterating the correlation with a window of $32 \times 32$ pixels $\left(320 \times 320 \mathrm{~m}^{2}\right)$ for the second step. Because of the shape of the correlation kernel the ground resolution is about half the size of the sliding window. We set a sliding step of 4-pixels. The corresponding ground sampling distance is thus $40 \mathrm{~m}$ but the resolution is of the order of $150 \mathrm{~m}$. For mitigating the effects of the high frequency noise on the accuracy of the correlation results, we set the frequency mask threshold as 0.9 and robust iteration as 2 .

Each correlation leads to displacement maps in the $\mathrm{E}-\mathrm{W}$ and $\mathrm{N}-\mathrm{S}$ directions. The signal to noise ratio on offset measurements is determined from the normalized cross spectrum. The $1-\sigma$ uncertainty is $\sim 20 \mathrm{~cm}$. The measurements show strong striping artefacts typical of jitter effects and CCD misalignments. In principle these artefacts can be modelled and mitigated during the orthorectification procedure but this was not possible as the raw images are not distributed by European Space Agency (ESA). Some orthorectification errors due to the DEM inaccuracies are also visible. We therefore mitigated these various artefacts with post-processing.

Misalignment of CCD arrays produces stripes in the along-track direction and are common obvious artefacts of pushbroom systems. These artefacts were removed by subtracting the average along-track value from each column in the along-track geometry. A second de-stripping was carried out to deal with the across-track stripes due to attitude oscillations of the satellite ("jitter"). De-trending step was carried out to the correlation maps by removing a linear ramp, determined from stable areas far from the fault rupture, in order to discard errors caused by orthorectification errors.

To separate the surface, the deformation between the two earthquakes that are closely spaced in time, by $\sim 34 \mathrm{~h}$, we use $3 \mathrm{~m}$ resolution Planet Scope imagery (see Supplementary Fig. 2) acquired by Planet Labs. We use the image correlation approach to measure the horizontal surface deformation with a window size of $32 \times 32$ pixels and step of 9 , and then apply a median filter $(3 \times 3$ pixels $)$ after correlation, which provides displacement at $\sim 15 \mathrm{~cm}$ precision $(1-\sigma)$. To measure the surface offset we use the COSI-Corr profiles orientated perpendicular to the fault trace with $8 \mathrm{~km}$ length and $\sim 1 \mathrm{~km}$ width, and extrapolate the linear regression fit to either side of the fault to estimate the total fault offset over the fault-zone.

Processing of high-rate GPS data. We processed 1-Hz continuous GPS data (see station distribution in Fig. S3a) from the Plate Boundary Observatory GNSS/GPS network for the day of the two events, respectively. GPS satellite orbits, Earth rotation parameters and $1-\mathrm{Hz}$ GPS satellite clocks were estimated using Positioning And Navigation Data Analysis software following the strategies described in Zhang et al. ${ }^{34}$. Precise point positioning ${ }^{35}$ is then employed to estimate epoch-wise positions together with receiver clock errors, zenith troposphere delays and phase ambiguities. Specifically, we assume no constraints between neighbouring epochs, receiver clocks are treated as white noise while troposphere delays as random-walk parameters with a process noise of $(1 \mathrm{~mm} / \mathrm{s})^{1 / 2}$. In addition, tidal displacements (solid Earth tide, pole tide and ocean tide loading) are modelled according to IERS Conventions $2010^{36}$. Antenna phase center offsets and variations are also corrected. All position estimates are aligned to the International Terrestrial Reference Frame (ITRF2008) and transformed into a local north, east, up frame.

SAR interferometric data. We obtained three radar images from the Advanced Land Observing Satellite 2 (ALOS-2) operated by the Japan Aerospace Exploration Agency and the Copernicus Sentinel-1 satellite operated by the ESA. The interferograms were processed by the JPL-Caltech ARIA team, which have been archived at https://aria-share.jpl.nasa.gov/20190704-0705-Searles_Valley_CA_ EQs/Interferograms/. The Sentinel-1 TOPS data were processed using InSAR Scientific Commuting Environment ${ }^{37}$. To form an interferogram with the shortest time span with the available acquisitions, the ALOS-2 interferogram is formed with ScanSAR-stripmap interferometry using a multi-mode InSAR processor added to ISCE ${ }^{38,39}$. Spatial and temporal coverage of SAR data are summarized in Supplementary Fig. 3.

Data preprocessing. We only use static GPS offsets within $100 \mathrm{~km}$ of the epicenter. The high-rate GPS displacement waveforms were low-pass filtered to 0.4 $\mathrm{Hz}$. Specifically, for the July $4 \mathrm{M}_{\mathrm{w}} 6.5$ event, we find the signal-to-noise level of the vertical components of the high-rate displacement waveforms is so low that we exclude them for inversion. To reduce the computational burden, we subsampled the InSAR data using the quad tree technique ${ }^{40}$ and a total of 2363 InSAR line of sight points were included for the joint inversion (see Supplementary Fig. 8). We use the residuals of the ALOS-2 (see Supplementary Fig. 11a) from July $6 \mathrm{M}_{\mathrm{w}}$ 7.1 to constrain the inversion of the July $4 \mathrm{M}_{\mathrm{w}} 6.5$ event.

We downloaded 35 teleseismic $\mathrm{P}$ ground recordings (see station distribution in Supplementary Fig. 9a) with $30^{\circ}$ to $90^{\circ}$ epicentral distances from IRIS. Instrument responses were deconvolved to retrieve displacement waveforms, which were then filtered with a bandpass filter at a $[0.005,0.4] \mathrm{Hz}$ corner frequency and decimated to $1 \mathrm{~Hz}$. We extracted 120 -s-long samplings from the raw data, starting $6 \mathrm{~s}$ prior to the clearest first arrival of the $\mathrm{P}$ waves. We manually aligned $\mathrm{P}$ wave initial motions to the theoretical arrival time predicted by velocity model of preliminary reference earth model (PREM) ${ }^{41}$.

Co-seismic rupture inversion. We perform a joint inversion based on ALOS-2 and Sentinel-1 measurements, static GPS offsets, 1-Hz GPS and broadband displacement waveforms using a multi-window code called Mudpy, which was originally developed by Melgar and Bock ${ }^{42}$

For the $M_{w} 7.1$ event, the fault geometry was constrained by the trace of the rupture at the surface, which implied a varying strike along the fault. To that end, we use three fault planes to represent the rupture geometries. For the $M_{w} 6.5$ event, in addition to the NE trending rupture that is recovered by the optical images, distribution of the aftershocks implies that it should have probably ruptured a conjugate fault, and we adopt two fault planes to model this event. Geometries of the two fault planes are determined based on the surface rupture trace and $\mathrm{W}$ phase moment tensor solutions. In terms of dip and rake angles, we assign their values based on global centroid moment tensor solutions ${ }^{43}$. All of the fault planes are further parameterized by a number of sub-faults along strike and dip, the detailed fault geometries are listed in Table S1.

The frequency-wavenumber integration $\operatorname{method}^{44}$ is adopted to compute Green's functions for every near-field data type (static GPS, InSAR, 1-Hz GPS displacement waveforms) using a 1-D layered velocity proposed by Mori and Helmberger ${ }^{45}$ as shown in Table S2. The teleseismic Green's functions are generated by propagator matrix approach ${ }^{46}$, velocity model by Mori and Helmberger ${ }^{45}$ is used for the source side and PREM ${ }^{41}$ is used for the receiver side. Besides, the same bandpass filter used for the waveforms is applied to the Green functions.

For each sub-fault, two vectors (see the vector rake angle in Table S1) are used and non-negative least square inversion is employed to account for the rakevarying slip. To recover the complexity of the sub-fault source time functions, we use 5 symmetric triangles with $3 \mathrm{~s}$ half-durations staggered by $1.5 \mathrm{~s}$ each for each sub-fault. To ensure a stability of the inversion result, we employ the first-order Laplacian regularization ${ }^{18}$. To calibrate the rupture speed in the inversion, we vary it between $1.2 \mathrm{~km} / \mathrm{s}$ and $3.4 \mathrm{~km} /$ in $0.2 \mathrm{~km} / \mathrm{s}$ bins, and the variance reduction as a function of rupture speed are plotted in Supplementary Fig. 4. We conclude that all the data are best explained by a maximum rupture speed of $1.8-2.0 \mathrm{~km} / \mathrm{s}$ for the $M_{w} 7.1$ event and $2.6 \mathrm{~km} / \mathrm{s}$ for the $M_{w} 6.5$ event.

Relative weighting always presents a tricky issue for joint inversion ${ }^{47}$. In this study, each kind of data is first normalized by their own norm and then different weighting factors are tested (see Supplementary Fig. 5), and we find that an equal weighting among GPS, InSAR and P waves can fit all datasets well.

For the joint inversion, we ran 25 iterations with various spatial and temporal smoothing levels and chose the favored one based on Akaike's Bayesian Information Criterion ${ }^{48}$, ABIC, against different smoothing factors as depicted in Supplementary Fig. 6. See comparison of observations and model predictions for the preferred slip model of $M_{w} 7.1$ event in Supplementary Figs. 7-9.

Supplementary Figs. 10 and 11 summarize the results of the $M_{w} 6.5$ event.

To investigate the resolution of inversion, we performed a standard checkerboard test, in which a synthetic checkerboard slip distribution (Supplementary Fig. 12) was built, and all the data used for the inversion were simulated. The checkerboard test shows that for the $M_{w} 7.1$ event, even the deep slip can be reliably recovered. For the $\mathrm{M}_{\mathrm{w}} 6.5$ event, however, a poor deep slip resolution is found due to a relatively sparse dataset.

In order to further estimate uncertainties of the inverted slips, we conducted a jackknife test, through which $20 \%$ of the data were randomly removed each time and inversion on the reduced datasets was repeated for 100 times. The standard deviation together with the coefficient of variation (the standard deviation divided by the slip) for the two events are shown on Supplementary Fig. 13. While the absolute variability of slip on each patch is indicated by the standard deviation, the coefficient of variation can be a better measure for showing which features are persistent.

Coulomb failure stress. Coulomb stress failure changes ( $\triangle \mathrm{CFS})$ on a plane can be described as ${ }^{49}$ :

$$
\Delta \mathrm{CFS}=\tau_{\beta}-\mu^{\prime}\left(\Delta \sigma_{\mathrm{n}}\right),
$$

where $\tau_{\beta}$ and $\Delta \sigma_{n}$ denote the shear and normal stress change, $\mu^{\prime}$ is the coefficient of effective friction. We analyze $\Delta$ CFS due to the $M_{w} 6.5$ event on the rupture fault planes of the $M_{w} 7.1$ event. Considering the focal mechanism of the $M_{w} 7.1$ event, we assume a uniform rake angle of $180^{\circ}$ for all of the three faults, the effective friction coefficient is set as 0.3 , and the shear module is set at $40 \mathrm{GPa}$. 


\section{Data availability}

The Sentinel-2 and Planet Labs images are stored at https://doi.org/10.5281/ zenodo.3542274 and https://doi.org/10.5281/zenodo.3542132, respectively. 1-Hz raw GPS observations are achieved by UNAVCO and publicly available at $\mathrm{ftp} / / /$ data-out.unavco. org/pub/highrate/1-Hz/rinex/2019/185 and ftp://data-out.unavco.org/pub/highrate/1-Hz/ rinex/2019/187. Static co-seismic GPS offsets are provided by the Nevada Geodetic Laboratory (http://geodesy.unr.edu/). The interferograms were generated from Sentinel SAR images from ESA and Japanese Aerospace Agency Advanced Land Observing Satellite 2, which were distributed by the ARIA team at the Jet propulsion Laboratory (https://aria-share.jpl.nasa.gov/20190704-0705-Searles_Valley_CA_EQs/Interferograms/). The broadband teleseismic seismograms are publicly available from Incorporated Research Institutions for Seismology (http://ds.iris.edu/wilber3/find_stations/11058875). The earthquake catalogues are obtained from the Southern California Earthquake Center at Caltech (http://service.scedc.caltech.edu/eq-catalogs/date_mag_loc.php). The focal mechanisms plotted in Fig. $2 \mathrm{~b}$ can be accessed at Global Centroid Moment Tensor catalogue (https://www.globalcmt.org/CMTsearch.html). All other data can be obtained from the lead author upon reasonable request (kjchen@caltech.edu).

\section{Code availability}

The Mudpy software package to invert the co-seismic slip distribution is available at https://github.com/dmelgarm/MudPy, the COSI-Corr software package is for free download from http://www.tectonics.caltech.edu/slip_history/spot_coseis/. The various scripts for Coulomb stress change calculation, data analysis and plotting are available from the authors upon request.

Received: 20 August 2019; Accepted: 19 November 2019; Published online: 07 January 2020

\section{References}

1. S.C.S, N. 07/04/2019, Searles Valley Sequence: M6.4 and M7.1. http://www. scsn.org/index.php/2019/07/04/07-04-2019-searles-valley-sequence/index. html

2. Lee, J., Spencer, J. \& Owen, L. Holocene slip rates along the Owens Valley fault, California: implications for the recent evolution of the Eastern California Shear Zone. Geology https://doi.org/10.1130/0091-7613(2001)0292.0.CO;2 (2002).

3. Oskin, M. \& Iriondo, A. Large-magnitude transient strain accumulation on the Blackwater fault, Eastern California shear zone. Geology https://doi.org/ 10.1130/G20223.1 (2004)

4. Oskin, M. et al. Elevated shear zone loading rate during an earthquake cluster in eastern California. Geology. https://doi.org/10.1130/G24814A.1 (2008)

5. Zeng, Y. \& Shen, Z. K. A fault-based model for crustal deformation, fault slip rates, and off-fault strain rate in California. Bull. Seismol. Soc. Am. https://doi. org/10.1785/0120140250 (2016)

6. Argus, G. R. G. Present tectonic motion across the Coast Ranges and San Andreas fault system in central California. Bull. Geol. Soc. Am. https://doi.org/ 10.1130/0016-7606(2001)113<1580:PTMATC>2.0.CO;2 (2001).

7. Peltzer, G., Crampé, F., Hensley, S. \& Rosen, P. Transient strain accumulation and fault interaction in the Eastern California shear zone. Geology https://doi. org/10.1130/0091-7613(2001)029<0975:TSAAFI>2.0.CO;2 (2001).

8. McGill, S. \& Sieh, K. Holocene slip rate of the central Garlock Fault in southeastern Searles Valley, California. J. Geophys. Res. 98, 14217-14231 (1993).

9. McGill, S. F., Wells, S. G., Fortner, S. K., Kuzma, H. A. \& McGill, J. D. Slip rate of the Western Garlock fault, at Clark wash, near lone tree Canyon, Mojave desert California. Bull. Geol. Soc. Am. https://doi.org/10.1130/B26123.1 (2009).

10. UNAVCO. Community event response to the July 4, 2019 M 6.5 and July 6, 2019 M 7.1 Earthquakes Near Ridgecrest, California, https://www.unavco.org/ highlights/2019/ridgecrest.html (2019).

11. Galetzka, J. et al. Slip pulse and resonance of the Kathmandu basin during the 2015 Gorkha earthquake, Nepal. Science 349, 1091-1095 (2015).

12. Melgar, D. \& Hayes, G. P. Systematic observations of the slip pulse properties of large earthquake ruptures. Geophys. Res. Lett. 44, 9691-9698 (2017).

13. Massonnet, D. et al. The displacement field of the Landers earthquake mapped by radar interferometry. Nature https://doi.org/10.1038/364138a0 (1993)

14. Van Puymbroeck, N., Michel, R., Binet, R., Avouac, J.-P. \& Taboury, J. Measuring earthquakes from optical satellite images. Appl. Opt. https://doi. org/10.1364/ao.39.003486 (2000).

15. Harris, R. A., Archuleta, R. J. \& Day, S. M. Fault steps and the dynamic rupture process: 2-D numerical simulations of a spontaneously propagating shear fracture. Geophys. Res. Lett. https://doi.org/10.1029/91GL01061 (1991).

16. Wesnousky, S. G. Predicting the endpoints of earthquake ruptures. Nature https://doi.org/10.1038/nature05275 (2006).
17. Avouac, J. P. \& Leprince, S. Geodetic Imaging Using Optical Systems. in Treatise on Geophysics 2nd edn https://doi.org/10.1016/B978-0-444-538024.00067-1 (Elsevier, Amsterdam, 2015).

18. Hartzell, S. H. \& Heaton, T. H. Inversion of strong ground motion and teleseismic waveform data for the fault rupture history of the 1979 Imperial Valley, California, earthquake. Bull. Seismol. Soc. Am. 73, 1553-1583 (1983).

19. King, G. C. P., Stein, R. S. \& Jian Lin. Static stress changes and the triggering of earthquakes. Bull. Seismol. Soc. Am. 84, 935-953 (1994).

20. Heaton, T. H. Evidence for and implications of self-healing pulses of slip in earthquake rupture. Phys. Earth Planet. Inter. https://doi.org/10.1016/00319201(90)90002-F (1990)

21. Nielsen, S. B., Carlson, J. M. \& Olsen, K. B. Influence of friction and fault geometry on earthquake rupture. J. Geophys. Res. Solid Earth https://doi.org/ 10.1029/1999jb900350 (2000).

22. Zheng, G. \& Rice, J. R. Conditions under which velocity-weakening friction allows a self-healing versus a cracklike mode of rupture. Bull. Seismol. Soc. Am. (1998).

23. Lu, X., Lapusta, N. \& Rosakis, A. J. Pulse-like and crack-like ruptures in experiments mimicking crustal earthquakes. Proc. Natl Acad. Sci. USA https:// doi.org/10.1073/pnas.0704268104 (2007)

24. Noda, H., Lapusta, N. \& Kanamori, H. Comparison of average stress drop measures for ruptures with heterogeneous stress change and implications for earthquake physics. Geophys. J. Int. 193, 1691-1712 (2013).

25. Bacon, C. R., Macdonald, R., Smith, R. L. \& Baedecker, P. A. Pleistocene highsilica rhyolites of the Coso volcanic field, Inyo County, California. J. Geophys. Res. https://doi.org/10.1029/JB086iB11p10223 (1981).

26. Yue, $H$. et al. The 2016 Kumamoto $M_{w}=7.0$ Earthquake: a significant event in a fault-volcano system. J. Geophys. Res. Solid Earth https://doi.org/10.1002/ 2017JB014525 (2017).

27. Zhang, Q. et al. Absence of remote earthquake triggering within the Coso and Salton Sea geothermal production fields. Geophys. Res. Lett. https://doi.org/ 10.1002/2016GL071964 (2017).

28. Haddon, E. K., Amos, C. B., Zielke, O., Jayko, A. S. \& Bürgmann, R. Surface slip during large Owens Valley earthquakes. Geochem. Geophys. Geosyst. https://doi.org/10.1002/2015GC006033 (2016).

29. Hough, S. E. \& Hutton, K. Revisiting the 1872 Owens Valley, California, Earthquake. Bull. Seismol. Soc. Am. https://doi.org/10.1785/0120070186 (2008).

30. Rockwell, T. K. et al. Paleoseismology of the Johnson Valley, Kickapoo, and Homestead Valley faults: clustering of earthquakes in the Eastern California shear zone. Bull. Seismol. Soc. Am. https://doi.org/10.1785/0119990023 (2000).

31. Dolan, J. F., Bowman, D. D. \& Sammis, C. G. Long-range and long-term fault interactions in Southern California. Geology https://doi.org/10.1130/G23789A.1 (2007)

32. Amos, C. B. et al. Chronology of tectonic, geomorphic, and volcanic interactions and the tempo of fault slip near Little Lake, California. Bull. Geol. Soc. Am. https://doi.org/10.1130/B30803.1 (2013).

33. Leprince, S., Barbot, S., Ayoub, F. \& Avouac, J. P. Automatic and precise orthorectification, coregistration, and subpixel correlation of satellite images, application to ground deformation measurements. IEEE Trans. Geosci. Remote Sens. https://doi.org/10.1109/TGRS.2006.888937 (2007).

34. Zhang, W. et al. Joint estimation of GPS/BDS real-time clocks and initial results. GPS Solut. 20, 665-676 (2016).

35. Zumberge, J. F., Heftin, M. B., Jefferson, D., Watkins, M. M. \& Webb, F. H. Precise point positioning for the efficient and robust analysis of GPS data from large networks. J. Geophys. Res. 102, 5005-5017 (1997).

36. Gérard, P. \& Luzum, B. IERS Conventions (2010). Bur. Int. Des Poids Mes. Sevres 1-179 (2010)

37. Roseu, P. A., Gurrola, E., Sacco, G. F. \& Zebker, H. The InSAR scientific computing environment. In Proc. European Conference on Synthetic Aperture Radar, (EUSAR, Nuremberg, Germany, 2012).

38. Liang, C. \& Fielding, E. J. Measuring azimuth deformation with L-band ALOS-2 ScanSAR interferometry. IEEE Trans. Geosci. Remote Sens. 55, 2725-2738 (2017).

39. Liang, C. \& Fielding, E. J. Interferometry with ALOS-2 full-aperture ScanSAR data. IEEE Trans. Geosci. Remote Sens. 55, 2739-2750 (2017).

40. Lohman, R. B. \& Simons, M. Some thoughts on the use of InSAR data to constrain models of surface deformation: noise structure and data downsampling. Geochem. Geophys. Geosyst. 6, Q01007 https://doi.org/ 10.1029/2004GC000841 (2005).

41. Dziewonski, A. M. \& Anderson, D. L. Preliminary reference Earth model. Phys. Earth Planet. Inter. 25, 297-356 (1981).

42. Melgar, D. \& Bock, Y. Kinematic earthquake source inversion and tsunami runup prediction with regional geophysical data. J. Geophys. Res. Solid Earth 120, 3324-3349 (2015).

43. Ekström, G., Nettles, M. \& Dziewoński, A. M. The global CMT project 2004 2010: centroid-moment tensors for 13,017 earthquakes. Phys. Earth Planet. Inter. 200-201, 1-9 (2012). 
44. Zhu, L. \& Rivera, L. A. A note on the dynamic and static displacements from a point source in multilayered media. Geophys. J. Int. 148, 619-627 (2002).

45. Mori, J. \& Helmberger, D. Large-amplitude moho reflections (SmS) from Landers aftershocks, Southern California. Bull. Seismol. Soc. Am. 86, 1845-1852 (1996).

46. Kikuchi, M. \& Kanamori, H. Inversion of complex body waves. Bull. Seismol. Soc. Am. 72, 491-506 (1982).

47. Chen, K., Feng, W., Liu, Z. \& Tony Song, Y. 2017 Mw 8.1 tehuantepec earthquake: deep slip and rupture directivity enhance ground shaking but weaken the tsunami. Seismol. Res. Lett. 89, 1314-1322 (2018)

48. Sekiguchi, H. Fault geometry at the rupture termination of the 1995 Hyogoken Nanbu earthquake. Bull. Seismol. Soc. Am. 90, 117-133 (2000).

49. King, G. C. P., Stein, R. S. \& Lin, J. Static stress changes and the triggering of earthquakes. Bull. Seism. Soc. Am. 84, 935-953 (1994).

50. Kreemer, C., Blewitt, G. \& Klein, E. C. A geodetic plate motion and Global Strain Rate Model. Geochem. Geophys. Geosyst. https://doi.org/10.1002/ 2014GC005407 (2014).

51. U.S. Geological Survey and California Geological Survey. Quaternary fault and fold database for the United States, (USGS, 2006) https://earthquake.usgs.gov/ hazards/qfaults/.

52. Salisbury, J. B., Rockwell, T. K., Middleton, T. J. \& Hudnut, K. W. LiDAR and field observations of slip distribution for the most recent surface ruptures along the central san Jacinto fault. Bull. Seismol. Soc. Am. https://doi.org/ 10.1785/0120110068 (2012).

53. Lozos, J. C. A case for historic joint rupture of the San Andreas and San Jacinto faults. Sci. Adv. https://doi.org/10.1126/sciadv.1500621 (2016).

54. Toppozada, T. \& Branum, D. California earthquake history. Ann. Geophys. (2004).

55. Rockwell, T. K. et al. Reassessment of the 1892 laguna salada earthquake: fault kinematics and rupture patterns. Bull. Seismol. Soc. Am. https://doi.org/ 10.1785/0120140274 (2015).

\section{Acknowledgements}

This work was partially supported by the National Science Foundation through grant EAR-182185. Part of this research was also supported by the National Aeronautics and Space Administration, and performed at the Jet Propulsion Laboratory, California Institute of Technology. We are grateful to ARIA project of the Jet Propulsion Laboratory for making their ALOS-2 and Sentinel-1 displacements publicly available and Cunren Liang for discussions of the InSAR data processing.

\section{Author contributions}

K.C. carried out finite source modelling and edited the paper; S.A. and C.M. processed optical offset data and edited the paper; J.P.A. conceived, supervised this study and edited the paper; F.Z. and C.S. processed the GPS data. All authors discussed the results and took part in finalizing this manuscript.

\section{Competing interests}

The authors declare no competing interests.

\section{Additional information}

Supplementary information is available for this paper at https://doi.org/10.1038/s41467019-13750-w.

Correspondence and requests for materials should be addressed to K.C.

Peer review information Nature Communications thanks Michael Oskin, Thomas Rockwell and the other, anonymous, reviewer(s) for their contribution to the peer review of this work. Peer reviewer reports are available.

Reprints and permission information is available at http://www.nature.com/reprints

Publisher's note Springer Nature remains neutral with regard to jurisdictional claims in published maps and institutional affiliations.

\begin{abstract}
(c) (i) Open Access This article is licensed under a Creative Commons cc. Attribution 4.0 International License, which permits use, sharing, adaptation, distribution and reproduction in any medium or format, as long as you give appropriate credit to the original author(s) and the source, provide a link to the Creative Commons license, and indicate if changes were made. The images or other third party material in this article are included in the article's Creative Commons license, unless indicated otherwise in a credit line to the material. If material is not included in the article's Creative Commons license and your intended use is not permitted by statutory regulation or exceeds the permitted use, you will need to obtain permission directly from the copyright holder. To view a copy of this license, visit http://creativecommons.org/ licenses/by/4.0/.
\end{abstract}

(C) The Author(s) 2020 